\title{
TEXTURE STUDY OF NATURALLY DEFORMED QUARTZITES FROM THE BETIC CORDILLERAS (SPAIN)
}

\author{
M-A. ALBERTINI ${ }^{\star}$,T. BAUDIN ${ }^{\star}{ }^{\star}$,J-C. GUEZOU ${ }^{\star}$ and R. \\ PENELLE ${ }^{*}$ daboratoire de Géologie structurale, URA 1369, Bat.504, \\ Univ.Paris Sud, 91405 Orsay Cedex. \\ **Laboratoire de Métallurgie Structurale, URA 1107, Bat 413, \\ Univ.Paris Sud, 91405 Orsay Cedex.
}

\section{INTRODUCTION}

Quartz is a major component of the metamorphic rocks. In order to use quartz as kinematic indicator, many geological works focused on crystallographic preferred orientation texture (fabric) of quartz have been done. Deformation and recristallisation textures are controled by various parameters (i.e. active slip systems, hydratation amount, deformation, temperature, pressure). A first step was to look for the main deformation mechanisms involved in textures of experimentally deformed quartzites (1)(2). A second step was to simulate the pole figures compared with those measured optically. Two major models was used, the"Taylor-Bishop-Hill" model which assumes homogeneous deformation (3)(4), and the over simplified Etchecopar approach (5) that assumes a $2 \mathrm{D}$ deformation and a single operative slip system. The relative good agreement between the experimental and the simulated pole figures led to use preferred orientation of the $\mathrm{C}$ axes as a tool in the determination or in the checking of bulk deformation suffered by geological samples.(6)

Until recently, the c-axis was the only direction which could be measured by optical techniques. The orientation of each grain about this axis is obviously no determined. The use of diffraction techniques such as neutron diffraction, and calculation of the orientation distribution function (ODF) (7)(8) allows a quantitative analysis of quartzite texture (9)(10)(11)

The aim of the present paper is to characterise the crystallographic texture of quartzite samples showing typical microstructures. A first attempt is to establish the relationships between microstructures and textures.

The studied samples were collected in the internal zones of the Betic cordilleras (Spain). The whole area studied shows a well defined foliation (S2) bearing a major stretching lineation (L2)(12). This lineation is generally oriented E-W and materialise direction and sense of the tectonic transport (it means direction and sense of rolling in metallurgical approach). 
The specimen coordinates have been chosen in a way that DN was the normal to the foliation plane, DL parallel to the lineation and DT in the foliation plane, normal to the lineation.

\section{MICROSTRUCTURE}

Microstructure of selected specimen can be classified according to the following criteria: boundary aspect, substructure, grain size and grain shape, which are markers of the deformation history. We can approximatively divide the samples into two microstructural groups: the "deformed" specimens, which are in fact partly recrystallized, and the "completely recrystallized" specimens. Deformation and recrystallization are very close tied in selected microstructures.

Rocks showing a hot deformation microstructure with associated a recrystallized microstructure will be named "deformed" specimens (fig. 1a,1b,1c). Coarse grains $(300 \mu \mathrm{m})$ are stretched in the foliation plane. They present a "flame" shape, and a marked substructure. This grain type can exist everywhere in the specimen (fig. 1a and 1b), or be located in bands parallel to the foliation plane (fig 1c). Small grains $(5-30 \mu \mathrm{m})$ are equant and generally surround large grains; They result from dynamic recrystallization of parentgrain. In some cases, neograins form a multilayer matrix parallel to the foliation plane (fig 1c). Mica flakes and others minerals exist but in small amount (5\%). Dynamic recrystallization can represent a large part of volume fraction of the samples (40\% in 89 $59,60 \%$ in $89-38,80 \%$ in $87-14)$. Other samples, show large subequant grains, which will be named "completely recrystallised" specimen (fig 1d and 1e). Grain size is homogeneous $(300-500 \mu \mathrm{m})$. The microstructure can be described as an elongated grain mosaic (89-33), mica are preferentially located at the grain boundaries. The regular grain shape could result from the relatively high mica content $(10 \%)$ preventing grain boundary migration perpendicularly to the foliation plane. Another "completely recrystallised" microstructure type (88-51) is a mosaic of grain relatively equant and large $(300-500 \mu \mathrm{m})$, but it remains some small grains $(50 \mu \mathrm{m})$. Foliation plane is weakly marked. Grain boundaries are straight. Mica $(<5 \%)$ are located at the quartz grain boundaries, but sometimes they are included inside the grain (due to grain growth).

\section{EXPERIMENT}

The neutron diffraction measurements on quartzites were performed at canal $6 \mathrm{~T} 1$ in Laboratory CNRS-CEA Leon Brillouin in Saclay, using a texture goniometer. The wavelength is $1.158 \mathrm{~A}$ and counting is an exploration of the half pole sphere which is cut in 1824 boxes of $3.75^{\circ} \times 5^{\circ}$. Complete pole figures are only determined in transmission, because of the low absorption coefficient of rocks for the neutron. In this method, data are only corrected of background, that is the reason why accuracy is good (13). 

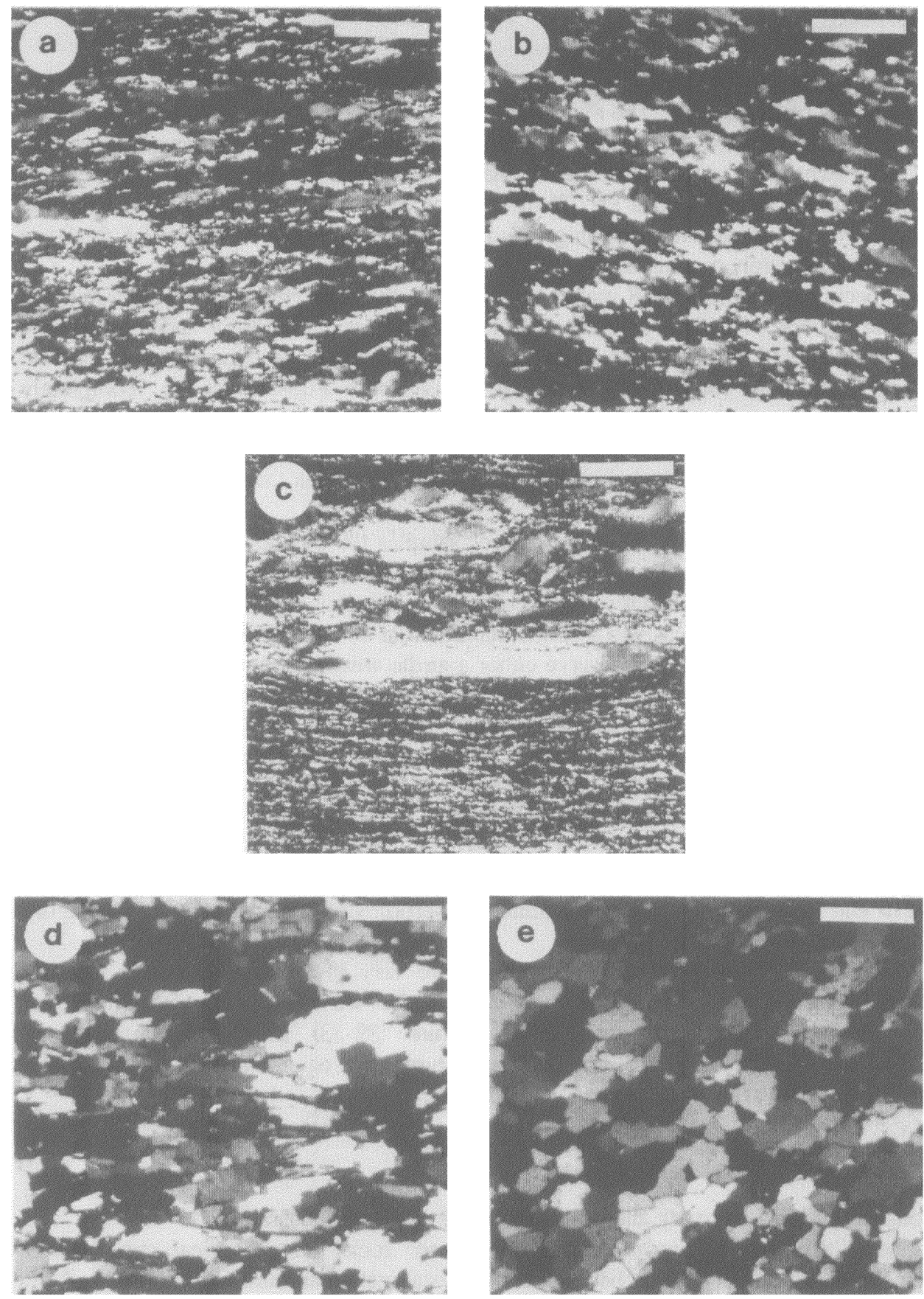

Fig. 1 - Microstructures of the quartzites.1/2 crossed nicols, (DL-DN) section. The foliation plane is perpendicular to the plate and E-W, the lineation is parallel to the plate. Scale bar $=500 \mu \mathrm{m}$. Samples number : a - 89-59; b-89-38; c-87-14; d-89-33; e - 88-51. 


\section{TEXTURE RESULTS}

From five measured pole figures (fig 2), the basal plane pole figure (0001) was regenerated from the ODF. The mathematical texture analysis up to the ODF calculation has been carried out using the series expansion method on spherical harmonic basis (7) up to an expansion order $1=10$. The calculation was done for the triclinic symmetry of the texture. The Euler angles Psi, Têtha and Phi are used. The lattice plane (hkil) and (khil) have the same lattice spacing in quartz, consequently pole figures of this type cannot be separately measured.

The specimens with an ODF maximum of 9, are the "deformed" ones, recrystallized volume fraction of which represent $40 \%$ to $60 \%$ (respectively $89-59$ and $89-38$ ). Pole figures and ODF values are less marked when the amount of dynamic recrystallized grains increase in rocks $(80 \%$ in $87-14$, in this case $F(g)<4)$. In the "completely recrystallized" sample (88-51 and 89-33), $F($ g) $<3$. Specimen 89-59 (fig. 2) present texture with a monoclinic symmetry, the plane (DN-DT) being the symmetry plane. This plane becomes less marked in other "deformed" samples, and does not exist in "recrystallized" ones.

The pole figures (0001) show for "deformed" samples (89-59 and 89-38) a single girdle containing one sharp maximum at $50^{\circ}$ to DT, or two maxima located at $40-50^{\circ}$ from DN in the (DN-DT) plane. When the amount of recrystallization increases (87-14), the girdle is larger and weaker and present a single maximum at $40^{\circ}$ from $\mathrm{DN}$. In the "completely recrystallized" specimens, we observe either a girdle weakly oblique to (DN-DT) plane with two maxima (89-33, one near DT, and the other near DN), or an oblique girdle with one of the two maxima near DN (88-51).

Sample containing a weak recrystallized part of dynamic recrystallization (89-59) present a clear texture: essentially $(10 \overline{1} 1)<11 \overline{2} 0>$ and $(11 \overline{2} 2)<10 \overline{1} 0-12 \overline{3} 0>$. In the sample with a more important recrystallized part (89-38), texture is more complex: essentially $(10 \overline{1} 1-11 \overline{2} 1)<1 \overline{2} 0-10 \overline{1} 0>$ but also $(11 \overline{2} 2)<12 \overline{3} 1>$. When dynamic recrystallisation is predominant $(87-14)$, the texture is less sharp, the components are: $(11 \overline{2} 2-11 \overline{2} 0)<11 \overline{2} 0$ $20 \overline{2} 1>$ and $(10 \overline{1} 3)<10 \overline{1} 0-21 \overline{3} 1>$. In summary, "deformed" specimens texture is roughly $(10 \overline{1} 1)<11 \overline{2} 0-10 \overline{1} 0>$.

In "recrystallised" samples, the ODF values are very low $(\mathrm{F}(\mathrm{g})<3)$, nearly isotrope values. Then we cannot conclude about texture, but we can show some tendancies. Samples with elongated mosaic microstructure (89-33) show two components: $(10 \overline{1} 4)<20 \overline{2} 1-12 \overline{3} 1>$ and $(20 \overline{2} 1)<11 \overline{2} 0\rangle$. The texture of the equant mosaic microstructure $(88-51)$ is $(10 \overline{1} 3)<12 \overline{3} 1-11 \overline{2} 0>$ and $(11 \overline{2} 1)<1 \overline{1} 1>$.

\section{CONCLUSION}

From this preliminary study, the following points can be emphasized.

Recrystallization is always present in "deformed" rocks (in geological meaning). It seems to exist a direct relation between the recrystallization amount $(40$ to $80 \%)$ and the ODF maxima (9 to 3 ). It is worth noting that ODF values are very weak for "completely recrystallized" samples $(\mathrm{F}(\mathrm{g})<3)$.

When recrystallization increases, we can note the obliteration of pole figure symmetry and a decreasing of the pole figure sharpness. 

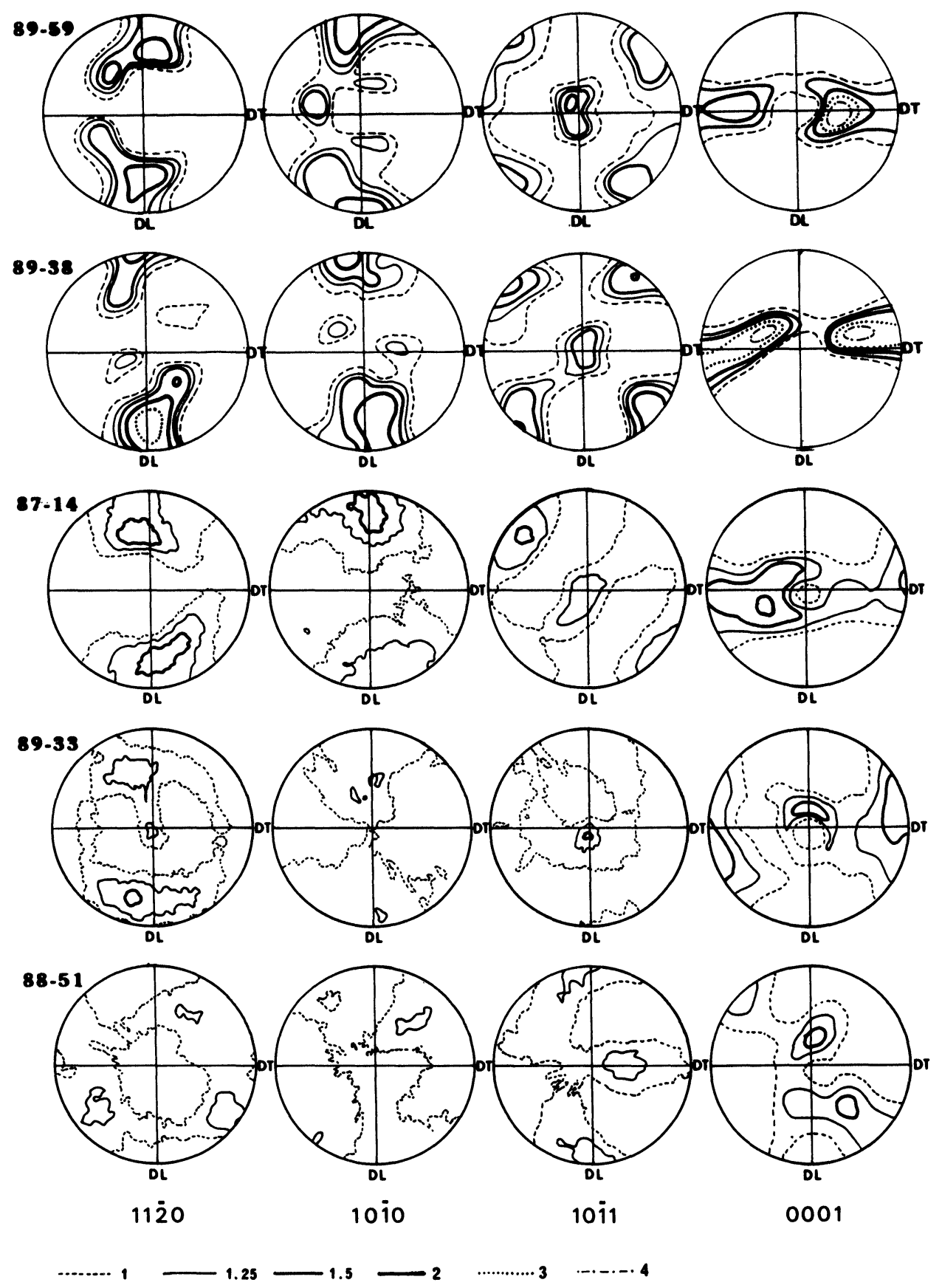

Fig.2 - Quartzites pole figures. (0001) is regenerated from the ODF, the others were measured directly. 
The (0001) pole figures evolve parallely with the recrystallization amount in the sample. Generally, authors compare C-axes crossed girdles and straight single girdle (3) related to precise kinematic framework. The projection plane in our study is the DL-DT plane, but usually authors works with the DL-DN plane. We have performed the rotation of the poles figures in order to better compare ours with those in litterature (20).

A comparative study with other data obtained by diffraction methods $(14,15,16,17,18,19)$,allows us to consider that "deformed" samples currently present the following texture: $(10 \overline{1} 1)<1 \overline{1} \overline{2} 0-10 \overline{1} 0\rangle$.

It is worth noting that a sample labelled "deformed" is in fact strongly recrystallized (8714), and have the same ODF values that a poorly deformed sample completely recrystallized $(88-51$ or $89-33, F(g)<3)$. Consequently, it appears that very strong "deformed" microstructures do not always correspond with pronounced crystallogaphic textures.

An important problem is to determine the exact contribution of dynamic recrystallization in a global texture. This will be the aim of futur works, using the Electron BackScattering Pattern techniques (EBSP).

1. J.Tullis et al.,Geol.Soc.Am.Bull.,81,p.297 (1973).

2. L.Dell'Angello and J.Tullis,Tectonophysics,169,p.1 (1979).

3. G.S.Lister et al.,Tectonophysics, 45,p.107 (1978).

4. G.S.Lister and B.E.Hobbs,J.Struct.Geol, 2,3,p.355 (1980).

5. A.Etchecopar,tectonophysics,39,p.121 (1977).

6. J.L.Bouchez et al.,Geol.Rdsch.,72,2,p.401 (1983).

7. RJ.Roe,J.Appl.Phys. ,36,2024 (1965).

8. H.J.Bunge and H.R.Wenk,Tectonophysics,40,p.257 (1977).

9. J.L.Bouchez et al.,Bull.Mineral.,102,p.225 (1979).

10.S.M.Schmid et al.,Tectonophysics,78,p.101 (1981).

11.D.W.Baker and H.R.Wenk,J.Geol.,80,p.81 (1972).

12.D.Frizon de Lamotte et al.,Geodinamica Acta,3,4,p.267 (1989).

13.P.Dervin and R.Penelle,Mémoires et Etudes Scientifiques,Revue de métallurgie,p.729 (1989).

14.N.S.Mancktelow,tectonophysics,135,p.133 (1987).

15.C.Simpson,doc. thesis, Zurich,266p.(1982).

16.R.D.Law et al.,J.Struct.Geol.,12,1,p.29 (1990).

17J.H.Behrmann,PHD Oxford,290p.(1982).

18.L.P.Dreschler et al.,Text.Microstruct.,8-9,p.737 (1988).

19.V.Damm et al.,Text.Microstruct.,12,p.15 (1990).

20.M.A.Albertini, T.Baudin, J-C.Guezou and R.Penelle,(to be published). 